\title{
Neurociência e Direito Penal: Discussões sobre a (Im)possibilidade de alteração no conceito de culpabilidade
}

\author{
Neuroscience and Criminal Law: Discussions on the \\ (Im)possibility of change the concept of culpability
}

Bruno Cavalcante Leitão Santos ${ }^{1}$ Marilia Maria Lopes Cursino ${ }^{2}$

\begin{abstract}
RESUMO
O presente estudo dedica-se a discussão das influências das descobertas da neurociência no direito penal, mais especificamente quanto a descoberta da ausência de liberdade nos indivíduos e a forma que o direito irá lidar com estas constatações. Propõe-se uma análise das teorias da culpabilidade e a evolução destas teorias ao longo da construção do direito penal. Dentro desta discussão analisa-se a dicotomia existente entre o livre-arbítrio e o determinismo, dualidade esta que causa parte da crise da culpabilidade, face a concepção dos neurocientistas de que a liberdade de vontade nunca existiu. O segundo momento deste trabalho será o aprofundamento quanto a forma que as experiências foram realizadas, culminando na observação se estas pesquisas foram direcionadas ao direito penal. Por fim, serão analisadas as doutrinas que tratam sobre o assunto, e em que direção os estudiosos estão se guiando para absolver as concepções neurocientíficas dentro do direito.
\end{abstract}

\section{PALAVRAS-CHAVE}

Direito Penal; Culpabilidade; Neurociência; Livre-arbítrio; Determinismo.

\begin{abstract}
The present study focuses on the influence of neuroscience discoveries in Criminal Law, more specifically on the discovery of the absence of freedom in humans and how Law will deal with those findings. It is proposed an analysis of theories of culpability and the evolution of those theories throughout the construction of Criminal Law. Within this discussion the dichotomy between free will and determinism is analyzed, this duality that causes part of the crisis of culpability, against the neuroscientist's conception that freedom of will never existed. The second moment of the work is the deepening as to the form that this experiences were realized, culminating in the observation if these investigations were directed to the Criminal Law.
\end{abstract}

\footnotetext{
${ }^{1}$ Doutor em Direito pela PUCRS; Mestre em Direito Público pela UFAL; Líder do Grupo de Pesquisa "Sistema Penal, democracia e direitos humanos"; Professor do Centro Universitário Cesmac e Faculdade FAMA; Editor da Revista Liberdades (IBCCRIM).

${ }^{2}$ Assessora Jurídica da $11^{\text {a }}$ Vara Cível da Comarca de Maceió-AL; Bacharel em Direito pelo Centro Universitário Cesmac.
} 
Finally, we will analyze the doctrines that deal with the subject, and in what direction scholars are going to absolve the neuroscientific conceptions within the Law.

\section{KEYWORDS}

Criminal Law; Culpability; Neurocience; Free will; Determinism.

\section{INTRODUÇÃO}

O Direito como parte das ciências sociais tem como finalidade precípua a regulação das condutas humanas, necessitando assim acompanhar as constantes mudanças ocorridas no meio social, ao passo que deve se valer das demais ciências com vista a atualizar, sempre que necessário, seus dogmas e princípios. Nesse sentido, vê-se necessário o estudo da possível influência de estudos de neurociência sobre o direito, em nossa análise no âmbito penal e, mais especificamente no tocante a culpabilidade.

Importa evidenciar que desde o ano de 1881, quando Franz Von Liszt delimitou delito como um ato antijurídico e culpável como pressuposto para a aplicação de uma pena, diversas foram as teorias que debateram sobre a culpabilidade, até chegar na atual definição de um juízo de valor dirigido àquele agente praticante de um ilícito penal.

Em meados de 1983, o psicólogo Benjamin Libet (2000) obteve a conclusão, através de pesquisas científicas, que os atos aparentemente voluntários são iniciados por um processo inconsciente do cérebro, que escolhe o movimento a ser realizado antes mesmo da sensação de consciência ocorrer. Por esta razão, foi difundido no meio científico a descoberta de que a liberdade (autonomia) não existiria, sendo todos os atos humanos determinados.

Cumpre evidenciar que a experiência realizada pelo autor teve como resultado a compreensão de que o potencial elétrico responsável pelo movimento provocado pelo cérebro tem início 0,8 segundo antes da percepção consciente e do movimento que, previamente, se imaginaria voluntário. Os dados apresentados foram capazes de trazer uma nova visão sobre a 
culpabilidade, e se esta apresenta um conteúdo compatível com as evoluções científicas como a trazida pelo pesquisador.

Sendo culpabilidade a reprovabilidade pessoal que incide sob uma conduta penalmente relevante praticada por um agente, estas descobertas apresentaram uma hipótese de mudança neste entendimento, tendo em vista que, para a análise do delito não mais será relevante a análise da conduta volitiva, e sim da determinação do agente sobre o resultado o qual esta conduta o determinaria a praticar.

Diante o exposto surge a seguinte problemática, com as descobertas do neurocientista Benjamin Libet, deverá o direito penal reformular suas considerações sobre o conceito de culpabilidade do agente infrator?

A primeira hipótese que se apresenta é a que o conceito de culpabilidade detém pressupostos seguros para não se alterar diante do aparente conflito com as conclusões apresentadas por Libet. A segunda hipótese, decorrente da primeira, será a de que as conclusões do experimento de Libet, e outros após ele, forçam o operador a questionar sobre os atuais critérios de imputação da responsabilidade penal, principalmente após as inovações comprovadas pela ciência nas últimas décadas, e uma possibilidade em rever seus dogmas.

A fim de abordar devidamente a temática, diante de sua variabilidade conceitual, utilizase de uma metodologia, quanto a sua base lógica, em uma abordagem hipotético dedutiva, e de cunho bibliográfico, efetivando nessa abordagem uma análise interdisciplinar entre pressupostos do direito penal e sua relação de interdependência com elementos da medicina e da psicologia, principalmente quanto ao ramo da neurociência cognitiva.

A narrativa em busca de inferências se dá a partir da análise sobre a evolução do conceito de culpabilidade no direito, demonstrado em um procedimentalismo histórico ao relembrar pressupostos de cada teoria da culpabilidade, analisando a dicotomia entre livre-arbítrio e determinismo.

Em seguida para análise das hipóteses apresentadas, serão analisadas as pesquisas neurocientíficas que levaram a uma suposta crise em relação ao conceito e operacionalização da culpabilidade, face à descoberta de que os seres humanos não possuem liberdade (autonomia) em suas decisões. 
Por fim, demonstrar-se-á as posições em que se encontram os doutrinadores do direito penal, suas análises sobre influências da neurociência sobre possíveis alterações na análise sobre o conceito de culpabilidade, ou mesmo da teoria do delito e controle dos indivíduos, e a conclusão sobre estas descobertas e suas reais possibilidades do ordenamento jurídico.

\section{A CULPABILIDADE NO DIREITO PENAL E A ANÁliSE DA REPROVABILIDADE SOBRE O AUTOR DO FATO DELITUOSO}

O crime, como hoje é compreendido na doutrina majoritária, é constituído por três requisitos: tipicidade, ilicitude e culpabilidade. A conduta será típica quando o ato humano adequar-se perfeitamente à norma penal. A ilicitude estará satisfeita quando a ação realizada for contrária à que se espera no ordenamento jurídico. O terceiro aspecto, a culpabilidade penal, é definida por Hans Welzel como um juízo de reprovabilidade que pressupõe um suporte específico, em sentido amplo “é a vontade de ação, antijurídica e culpável” (2011, p. 111).

Para que o agente seja punido pelo ato realizado, sua conduta deverá, inicialmente, cumprir com os três requisitos citados, ou seja, deve ser típica, ilícita e culpável. Necessariamente estes requisitos devem ser cumpridos na forma que foram dispostos e, não havendo preenchimento de um deles, o autor não sofrerá punição. Por outro lado, entendendo o representante do Parquet que todos os elementos foram satisfeitos, o ato considerar-se-á crime, devendo este órgão ministerial defender a pretensão acusatória.

A culpabilidade é um requisito do delito que recebe uma atenção especial dos doutrinadores, tendo Zaffaroni e Pierangeli (2009, p. 517) inclusive citado ser "o mais apaixonante estrato da teoria do delito". Conceituando o tema apresentado os autores são objetivos ao afirmarem que culpabilidade "é a reprovabilidade do injusto ao autor" e que este seria "um conceito de caráter normativo, que se funda em que o sujeito podia fazer algo distinto do que fez, e que, nas circunstâncias, lhe era exigível que o fizesse”.

Em verdade esse que é o conceito meio usual decorre da jurisprudência do Tribunal Federal Alemão, identificando-a como “um juízo de reprovação pessoal, feito a um autor de um 
fato típico e antijurídico, porque, podendo se comportar conforme o Direito, optou por comportar contrário ao Direito" (BRANDÃO, 2015, p. 112)

Juarez Cirino dos Santos, ao realizar o conceito de culpabilidade, expõe os elementos que considera formadores da mesma, ao citar ser:

Um juízo de reprovação sobre o sujeito (quem é reprovado), que tem por objeto a realização do tipo de injusto (o que é reprovado), que tem fundamento (a) a capacidade geral de saber (e controlar) o que faz, (b) o conhecimento concreto que permite ao sujeito saber realmente o que faz, e (c) a normalidade das circunstancias do fato que confere ao sujeito o poder de não fazer o que faz (porque é reprovado), expectativa aleatória tenha se tornado definitivamente impossível (2008, p. 282).

Na mesma linha de raciocínio encontra-se Cláudio Brandão, que em sua obra apresenta a conceituação de culpabilidade como "juízo de reprovação pessoal, feito a um autor de um fato típico e antijurídico, porque, podendo se comportar conforme o direito, o autor do referido fato optou livremente por se comportar contrário ao direito" (2008, p. 201).

Cezar Roberto Bitencourt, em seu turno, traz uma definição mais contextualizada ao citar que culpabilidade é "um juízo individualizado de atribuição de responsabilidade penal e representa uma garantia para o infrator frente aos possíveis excessos do poder punitivo estatal" (2014, p. 436).

Percebe-se, pela leitura dos conceitos dos diferentes autores, que é notório o elemento da reprovação presente na culpabilidade. $\mathrm{O}$ agente delituoso deverá responder pelo agir diverso do esperado, tendo em vista a reprovabilidade intrínseca de sua conduta. Além disto, a voluntariedade é característica presente, ou seja, o indivíduo realizou uma escolha de se portar de maneira diversa à prevista na norma, ou, observando juridicamente, adequou-se àquele ato o qual a lei prevê responsabilização.

No entanto, várias foram as alterações realizadas no conceito de culpabilidade, que vagou pela ideia de ser necessário apenas o nexo causal entre conduta e resultado, até que hoje fosse entendida, em curtas linhas, como o juízo de reprovabilidade direcionado ao autor de um delito, alterações estas a serem destrinchadas ao longo do estudo. 


\subsection{Análise do desenvolvimento do conceito de culpabilidade como elementar do crime: principais concepções e alterações ao longo da transformação do conceito de delito}

A evolução das teorias da culpabilidade seguiu a mutação do sistema de penalização, ou seja, com o avanço do entendimento de como deveriam ser as medidas punitivas para aqueles que cometiam delitos, o entendimento quanto a culpabilidade penal modificou-se.

O ato ilícito culpável foi analisado desde o início da civilização humana, quando os indivíduos conviviam em tribos mas já entendiam que deveria haver uma punição aos atos realizados com resultados danosos, como por exemplo entre os povos primitivos e sua crença no castigo sobrenatural em caso de violação das proibições totêmicas (FREUD, 2013), como ressalta Oswaldo Henrique Duek Marques, pois “a ideia de contaminação de todo o clã pela ofensa fez com que, pouco a pouco, a responsabilidade recaísse sobre o transgressor e sua punição fosse aplicada pela própria comunidade" (2008, p. 18). A responsabilidade durante este período era entendida como objetiva, isto é, havendo atentado à paz existente, aquele que o causou deverá ser punido, independentemente de ter desejado o resultado alcançado.

Passado esse período essencialmente de vingança, com responsabilidade objetiva, mas já de caráter social, como bem ressalta Luis Jimenez de Asua ao indicar que "la reacción social de que hablamos es em su origen eminentemente religiosa, y solo de modo paulatino se hace civil” (1950, p. 206), passa a se formar novas convicções na Idade Média, influenciadas por uma nova espiritualidade, a sabedoria cristã onde a justiça se pautava pelo fato de que o indivíduo cometeu o ato ilícito à ele imputado, e que por possuir o livre-arbítrio, concedido por Deus, tendo a possibilidade de escolher como se comportar, voluntariamente não o fez.

Segundo disposição de Paulo César Busato e Sandro Montes Huapaya, na Idade Média o entendimento que predominava baseava-se na ideia de que:

\footnotetext{
A capacidade de imputação significava então que uma ação pertenceria ao autor que livremente optou por ela, e nisso consistiria a base moral de reprovação do comportamento. $\mathrm{O}$ fundamento filosófico era evidentemente relacionado com a ideia de que Deus, criando o homem como sua imagem e semelhança, dotando-o de livrearbítrio, permitia-lhe a opção por escolher entre o bem e o mal (2007, p. 145).
}

Ultrapassados os pensamentos da Idade Média, formulou-se os seguimentos da Escola Clássica e a Escola Positiva Italiana, tendo a primeira como base o pensamento de que não bastava apenas o nexo causal entre conduta e resultado danoso, a pena só poderia ser aplicada 
às condutas que possuíam o elemento subjetivo direcionado ao dano. Por sua vez, contando com Lombroso e Garófalo como principais expoentes, a Escola Italiana trouxe o viés determinista, oposto do livre arbítrio, e apresentou o criminoso nato, passível não de pena, mas de cuidados, tendo em vista não ser analisada a sua culpabilidade, mas sim sua periculosidade.

Dentro desta evolução quanto a responsabilização criminal, iniciada de forma objetiva e culminando na subjetiva, diversas teorias foram criadas como forma de justificar os conceitos de culpabilidade que se alteraram com o tempo. A primeira teoria desenvolvida continha uma concepção psicológica-naturalista, que imperou no fim do Século XIX tendo como principais exponentes von Liszt e Beling, onde a culpabilidade foi considerada o vínculo psicológico responsável pela interligação da conduta do agente com o resultado alcançado, ou seja, o fato ilícito produzido. Juarez Cirino dos Santos ressalta que:

O conceito psicológico de culpabilidade é formado por dois elementos: a) a capacidade de culpabilidade (ou imputabilidade), como capacidade geral ou abstrata de compreender o valor do fato e de querer conforme a compreensão do valor do fato, excluída ou reduzida em situações de imperfeição (imaturidade) ou de defecção (doença mental) do aparelho psíquico; b) a relação psicológica do autor com o fato, existente como consciência e vontade de realizar o fato ou como causação de um resultado típico por imprudência, imperícia ou negligência (2010, p. 275).

Vê-se aqui que os defensores da teoria psicológica-normativa a separavam em dois pontos, sendo o primeiro deles externo, que concebia a conduta típica e antijurídica, e o segundo interno, referente ao vinculo psicológico que passou a ser chamado de culpabilidade. Esta teoria passou a aprofundar os sentidos de dolo e culpa, estabelecendo a interligação entre ação e dano através deles.

Esse nova perspectiva que surge em 1907 com Frank, e é aperfeiçoada por Mezger e Goldschmidt, indica que a culpabilidade não é mais apenas um vínculo psicológico entre sujeito e fato, mas um juízo de reprovação sobre o agente, tendo como suporte para essa análise uma normatização pelo direito em um tipo que identifica o dever ser (BRANDÃO, 2015).

Luiz Regis Prado (2014) ressalta que por não tratar sobre condutas omissivas, da coação irresistível, bem como sobre lidar com casos de estado de necessidade exculpante, esta teoria foi duramente criticada e superada pela teoria normativa. Já que sua previsão de que a culpabilidade, na realidade, tratava-se de um juízo de censura, e não de um aspecto psicológico, deveria observar toda a estrutura ao redor agente e se existiria possibilidade de determinar-se 
para alcançar o resultado almejado pela sociedade, e partir daqui, começou-se a entender a exigibilidade de conduta diversa dentro do conceito de culpabilidade.

A compreensão normativa demonstrou através de Hans Welzel, seu principal defensor, que não havia a possibilidade do dolo encontrar-se dentro da culpabilidade, contrapondo as convicções da teoria anterior, tendo em vista que este deve ser observado dentro da conduta humana. Saindo da culpabilidade, o dolo passou a encontrar-se na tipicidade, o autor deixa isso claro ao indicar que "o conceito de culpabilidade, como tal, não compreende, ao contrário, elementos subjetivos anímicos e conserva apenas o critério normativo da reprovabilidade, com base no qual se examina se a vontade de ação é culpável (2011, p. 114).

Regis Prado (2014) defende a não existência de uma só teoria normativa e sim uma variedade destas, citando entre elas a teoria finalista, considerada como a que superou os pensamentos normativos anteriores.

Esta teoria da ação final (finalista) afastou o dolo da culpabilidade, passando a observar principalmente se na ação praticada houve intenção de alcançar determinado resultado. Conforme preleciona Welzel, e em concordância com esta teoria, a culpabilidade "é a reprovabilidade de decisão da vontade" (1964, p. 80). Comprovada esta intenção, passível será o agente de sofrer responsabilização.

Definindo ação como fenômeno social, a teoria social da ação foi enraizada por Eb Schimidt, superou a teoria finalista e, como indica Rogério Greco (2014), procurou englobar aspectos do causalismo e do finalismo. Esta teoria rapidamente encontrou opositores, podendo ser citado o doutrinador Juarez Tavares (1980), que apostou em dois pontos principais que demonstravam as dificuldades desta, sendo eles o óbice em fornecer uma conceituação para relevância social da conduta e a inutilidade prática de um conceito de ação que justifique uma valoração desta ordem.

A teoria social da ação foi rapidamente superada pela teoria funcionalista, trabalhando com dois vieses: a imputabilidade objetiva e culpabilidade atrelada a responsabilidade criminal. Rogério Greco cita que “como o próprio nome está a induzir, o funcionalismo parte dos pressupostos político-criminais ligados diretamente às funções do Direito Penal” (2014, p. 390). 
Apesar das diferenças existentes entre as diversas teorias, estas se baseiam na voluntariedade do agente em produzir uma conduta, ou seja, no livre-arbítrio existente. A definição de livre-arbítrio centraliza-se, essencialmente, na livre oportunidade que o ser humano possui em escolher as decisões que fará em sua vida.

Se há um ponto em comum dentre os vários autores associados a Escola Clássica é sobre sua racionalização, em que "a pena é baseada - em maior medida - na retribuição moral, e o delito como ente jurídico" (RODRÍGUEZ, 2018, p. 152) ambos associados a uma ideia contratualista sobre o Estado.

Por algum tempo, pelo direito penal, a concepção de livre-arbítrio entrou em choque com a ideia do determinismo que, ao contrário daquela teoria, entende que todas as decisões do ser são pautadas por conceitos preexistentes, interna e externamente, que afetam diretamente suas escolhas. Trazendo a culpabilidade para esta discussão, surge o seguinte questionamento: entendendo pela existência da liberdade de agir e, consequentemente, pelo livre-arbítrio, as pessoas que cometem atos contrários à lei fizeram esta escolha por vontade própria e deverão ser punidas conforme o ordenamento jurídico ou, acreditando no panorama determinista, estas escolhas não foram livremente realizadas e os atos errôneos executados pelos agentes não são passiveis de punição considerando a ausência de liberdade em suas ações?

A dicotomia entre livre-arbítrio e determinismo se mantém ao longo das evoluções doutrinárias e pesquisas cientificas, principalmente pela dificuldade em comprovar a existência da liberdade e pelos avanços da neurociência que progridem para demonstrar que a livre escolha jamais existiu. Estas concepções trazem consequências diretas para o direito penal haja vista ser a liberdade de escolha a base central da culpabilidade como entendida atualmente. Segundo disposição de Cezar Roberto Bitencourt "o livre arbítrio como fundamento da culpabilidade tem sido o grande vilão na construção moderna do conceito de culpabilidade e, por isso mesmo, é o grande responsável pela sua atual crise" (2009, p. 357).

Como forma de solucionar essa problemática, os estudiosos do direito passaram a esmiuçar as pesquisas realizadas na neurociência, observando não só a forma como estas foram realizadas, mas tentando encontrar um ponto de significância entre as condutas perpetradas, que geraram as conclusões sobre a ausência de liberdade, e as ações penalmente relevantes. 


\section{OS ESTUDOS DA NEUROCIÊNCIA E SUAS POSSÍVEIS INFLUÊNCIAS NO DIREITO PENAL}

A neurociência, amplamente divulgada nos meios intelectuais na atualidade, abrange o estudo do sistema nervoso, assim como de todas as conexões que este realiza com o corpo humano, inclusive analisando as atividades cerebrais e o agir comportamental do homem. Possui como objetivo principal compreender o "fluxo de sinais elétricos através de circuitos neurais que origina a mente - como percebemos, agimos, pensamos, aprendemos e lembramos" (KANDEL, 2014)

Seu uso habitual abrange o estudo dos reflexos no sistema nervoso causados por doenças neuronais, assim como a possibilidade de tratamento destas doenças e suas prevenções.

Partindo da Medicina clássica, com expoentes como Hipócrates, estudando o prazer e a dor, atravessando o Renascimento com o cientista Leonardo da Vinci e seus estudos empíricos dos ventrículos cerebrais (BLANCO, 2014), para chegar em pesquisadores como Benjamin Libet e seus estudos sobre autonomia, esta ciência mantem-se em evolução utilizando-se das descobertas tecnológicas para ampliar seus conhecimentos e desvendar os mecanismos neuronais e fisiológicos do corpo e da mente humana.

Dentro da neurociência, tem-se como campo de estudo significativo àquele que busca entender como funcionam mecanismos de escolha, percepção, memória, raciocínio e atenção dos indivíduos. A razão desta ampla pesquisa encontra-se no fato de que a partir dela pode-se entender um pouco mais sobre o funcionamento da consciência e da inconsciência humana.

Face a necessidade atual de dar mais atenção à saúde mental e as diversas formas de alcança-la, a neurociência elevou suas pesquisas e descobertas nas últimas três décadas em busca de explicações para as causas dos comportamentos humanos, desde os mais simples aos mais complexos (GORGA; MARCHIONI, 2015).

Sua interligação com o direito penal se dá no momento em que as pesquisas neurocientíficas adentram na análise da atuação humana, e em como esta ação se projeta no dia-a-dia dos homens. Os primeiros grandes pesquisadores a introduzirem ideias da neurologia, 
psiquiatria e neurociência ao direito penal foram Cesare Lombroso e Sigmund Freud, tendo o primeiro sido o precursor da antropologia criminal, criando a ideia de criminosos natos que possuíam características físicas em comum, enquanto o segundo é considerado o pai da psicanálise, tendo estudado os processos inconscientes, pré-conscientes e conscientes envolvidos nos sonhos visando entender os estágios de funcionamento da mente (FREUD, 1990).

Hoje, em razão dos avanços da tecnologia, novas percepções sobre a mente estão sendo encontradas e, como citado por Maria Luiza Gorga e Guilherme Lobo Marchioni (2015, p. 106), "a própria mente passa a ter causa, o que levanta diversas questões a respeito da imputabilidade e do livre-arbítrio". E, em sendo a liberdade de ação a base do entendimento da culpabilidade, não há como deixar de antever a influência destas pesquisas dentro do âmbito jurídico penal.

\subsection{As descobertas de Benjamin Libet quanto as ações inconscientes do ser humano}

Não é recente a tentativa da neurociência em demonstrar que, em muitos casos juridicamente relevantes, o ato do ser humano foi causado por uma falsa sensação de liberdade de escolha, sendo na verdade determinado por aspectos neurológicos. Cite-se, entre a comunidade acadêmica, os estudos sobre o caso de um indivíduo que durante sua vida adulta jamais apresentou sinais de distanciamento do padrão normal de sexualidade mas que, sem razão aparente, passou a interessar-se pela pedofilia. A mudança de comportamento o levou a um especialista, tendo este localizado em seu cérebro um tumor precisamente fixado na área cerebral que controlava a alteração de comportamento e o julgamento (GORGA; MARCHIORINI, 2015).

Neste diapasão, citam os autores:

A repentina aparição de impulsos pedófilos ilustra o quadro que a neurociência vem
traçando, é o retrato do argumento de que, quando a biologia se altera, igualmente, se
operam mudanças na tomada de decisões, de que os impulsos de uma pessoa
dependem de questões intricadas da máquina neuronal (preferencias, como atração
por crianças/adultos, agressividade/passividade, etc.) (GORGA; MARCHIORINI,
2015, p. 113).

Por constatações como a acima explicitada, e ao perceber que após a retirada do tumor o comportamento do indivíduo voltou ao normal, a neurociência começou uma verdadeira 
caçada para demonstrar a ausência de liberdade nas condutas do ser humano. De diversas formas, os cientistas começaram a tentar demonstrar empiricamente que o problema não está no fato de que não há como provar que a liberdade existe, e sim de que se comprova que ela jamais existiu.

Utilizando-se dos resultados obtidos com as técnicas cientificas, como a ressonância magnética (KANDEL, 2014) para analisar as sinapses realizadas pelo cérebro no momento da tomada de uma decisão, os neurocientistas passaram a guiar-se através de um viés determinista ao ditar que a liberdade não existiria.

Estes estudos foram amplamente divulgados no fim do século passado quando foram difundidas no meio cientifico as descobertas realizadas pelo psicólogo e neurocientista Benjamin Libet. Este norte-americano realizou pesquisas no intuito de estabelecer um parâmetro temporal entre o início de uma conduta e a voluntariedade em sua realização (LIBET, 2000).

Os testes e experimentos não invasivos realizados por Libet guiavam-se pelo posicionamento de eletrodos no couro cabeludo de voluntários para captar as alterações das atividades neuronais e de aparelhos capazes de registrar movimentos dos músculos em suas mãos e braços, antes de pedir que estes pensassem no movimento que gostariam de realizar e mexessem o dedo da mão direita ou da mão esquerda, informando o momento exato em que “teriam tomado esta decisão" (LIBET, 2000).

Analisando as sinapses do cérebro destas pessoas, a pesquisa concluiu que o impulso que gera o movimento age na porção inconsciente do cérebro humano e anteriormente à tomada de consciência. Ou seja, antes do momento em que a cobaia informou ter tomado a decisão, as sinapses cerebrais já haviam iniciado, e foram estas sinapses ocorridas inconscientemente as responsáveis pelo movimento (BUSATO, 2014).

De forma objetiva, a escolha de agir foi tomada antes da percepção dos agentes, não tendo esta possibilidade de decisão quanto ao início da ação, apenas sobre como controlar o ato. Libet como conclusão de seu estudo, descreveu:

Nós temos liberdade? Eu realizei uma experiência para essa questão. Atos de liberdade voluntários são processados por uma específica mudança elétrica no cérebro (the 'readiness potential', (RP - potencial de prontidão) que começa 550 
milissegundos antes da ação. A subjetividade humana que produz a intenção do ato vem 350-400 milissegundos depois que o RP começa, mas 200 milissegundos antes da atividade motora. O processo voluntário é, portanto, iniciado inconscientemente. Mas, a atividade funcional do consciente ainda pode controlar o resultado; pode vetar o ato $(2000$, p. 48).

A partir destas constatações, os pesquisadores da área neurocientífica começaram a difundir que encontraram provas empíricas que demonstram a ausência de liberdade na ação humana, tendo em vista esta ser realizada inconscientemente antes, e apesar, da consciência do homem, que apenas tem um reflexo desta decisão.

Apesar de revolucionárias, as constatações de Libet sofreram críticas entre a comunidade acadêmica. Nas lições de Fabio André Guaragni e Rodrigo Régnier Chemim Guimarães, "foi questionado se os julgamentos de tempo eram confiáveis, uma vez que o tempo de janela entre a intenção relatada e o movimento foi muito curto (cerca de meio segundo)" (2014, p. 181). Além disto, com o passar do tempo e o avanço da tecnologia, foram questionados se os aparelhos utilizados no experimento teriam constatações confiáveis, haja vista que não marcariam a percepção cerebral como as máquinas que hoje existem.

Porém, independente das críticas, não há como negar que as pesquisas realizadas por Libet deram o passo inicial para que novas investigações fossem realizadas, cada uma delas avançando um pouco mais nas descobertas face a utilização de aparelhos com capacidade superior aos utilizados pelo pesquisador. Além disso, as proporções das constatações do cientista ultrapassaram as fronteiras dos Estados Unidos e, como bem cita José Francisco Leyton Jimenez:

Estas investigaciones fueron tomando considerable fuerza. En el año 2004, em Alemania, once científicos publicaron un manifiesto en que daban cuenta de que los avances neurocientíficos cambiarían radicalmente la forma en que se entenderia el mundo en los próximos años, señalando un reduccionismo importante: "todos los procesos psíquicos internos pueden ser descritos en términos de câmbios físicoquímicosente (2014, p. 67).

Os experimentos realizados por Libet repercutiram de forma tão relevante, principalmente no meio cientifico, que foram posteriormente executados por pesquisadores ao redor do mundo, sendo possível citar entre eles Patrick Haggard, John-Dylan Haynes, Marcel Brass e Chun Siong Soon.

Os três últimos cientistas supracitados chegaram a realizar uma experiência (2008) que possuía estreita similitude com a realizada por Libet: posicionaram pessoas em frente a uma 
tela onde diversas letras iriam passando, tendo estes indivíduos sido orientados a apertar um botão quando tivessem vontade, devendo memorizar a letra demonstrada quando do momento desta decisão. Posteriormente, deviam as cobaias identificarem, em outra tela, a letra que teria aparecido no momento da decisão. O resultado encontrado por Soon, Brass e Haynes foi o seguinte:

Aqui nós mostramos que o resultado de uma decisão é codificado na atividade cerebral do córtex pré-frontal e parietal em até dez segundos antes de se tornar consciente. Este atraso presumivelmente reflete a operação de uma rede de áreas de monitoramento de alto nível que começam a preparar uma decisão que está por vir muito antes dela entrar na consciência (GUARAGNI, 2014, p. 183).

As conclusões alcançadas pelos cientistas comprovaram e melhor explanaram o anteriormente descoberto por Libet e suas pesquisas foram refeitas inúmeras vezes ao longo do tempo, tendo todas as respostas partido para o mesmo sentido de que a atividade cerebral decisória é iniciada previamente à consciência do indivíduo, não tendo este escolha quanto a decisão tomada.

Menciona-se, também, que alguns pesquisadores foram ainda mais longe, buscando novas formas de comprovar que as decisões realizadas pelo ser humano são previamente pautadas e podem ser influenciadas quando o cérebro é estimulado.

Álvaro Pascual-Leone e Isaac Túnes Fiñana (2014), em seus experimentos com técnicas não invasivas ao cérebro, conseguiram comprovar que ao gerar impulsos eletromagnéticos em direção a certa região do cérebro existe a tendência do indivíduo realizar uma escolha determinada. Pedindo para suas cobaias mexerem uma das mãos, os autores descobriram que ao estimular um dos hemisférios do cérebro a decisão sobre mexer a mão direita ou esquerda poderia ser influenciada, sendo exponencialmente maior a escolha por uma das mãos quando o hemisfério cerebral certo era incitado.

Fica clara a tentativa dos pesquisadores da área da neurociência em destrincharem o funcionamento do cérebro humano, mais especificamente em como este órgão funciona em momentos decisórios. As respostas destas pesquisas alcançaram o direito penal, sendo este forçado à avaliar tais conclusões e confrontá-las frentes a seus dogmas. 


\section{OS REFLEXOS DAS DESCOBERTAS DA NEUROCIÊNCIA NO DIREITO PENAL}

As constatações de Libet trouxeram à tona a infindável discussão sobre o determinismo do agente em suas ações do dia-a-dia. Sendo cientificamente comprovado que as decisões do homem são tomadas antes que o mesmo tenha a percepção disto, e que o movimento a ser realizado por este não tem interligação com as sinapses da decisão consciente, como entender pela existência de um livre-arbítrio? Não existindo, então, livre-arbítrio, como se falar com culpabilidade como juízo de reprovabilidade de um autor que, podendo agir de outro modo, agiu contra o direito?

A problemática existente nesta apuração reside no fato de que não seria possível entender como culpável/reprovável a conduta do agente, considerando que este não tem influência na decisão sobre a realização desta ação e poderá apenas controlar os reflexos deste ato inconscientemente realizado, pois, segundo Libet, a consciência poderá vetar o resultado da ação (LIBET, 2000).

Deste modo, o conceito de culpabilidade hoje aceito teoricamente perderia sua significação, tendo em vista a comprovação de que a punição do agente não deve recair sobre a conduta que realiza, ao considerar que esta não é conscientemente efetuada, e sim sobre os resultados advindos desta conduta, e da possibilidade, ou não, de se comprovar que o agente teria a capacidade de agir de outro modo e de controlar sua ação para atingir resultados aceitos juridicamente.

Paulo Busato indica que:

Resumidamente, é possível dizer que a crise do princípio de culpabilidade está intimamente relacionada à impossibilidade ou dificuldade de comprovar que o agente, no caso concreto, poderia ter atuado de outro modo, ou seja, poderia ter obedecido ao ordenamento jurídico, e à igual impossibilidade de afirmar com certeza, quais são as condicionantes empíricas que incidem sobre a atuação criminosa do sujeito e em que medida elas são determinantes desta atuação. A eventual admissão da impossibilidade de demonstração de que o sujeito poderia agir conforme o direito conduziria, em princípio, à renúncia da culpabilidade como fundamento e também como baliza da pena, pois se não é possível demonstrar que o sujeito poderia ter agido de outro modo, tampouco é possível responsabiliza-lo por sua escolha e, se não é possível mensurar as opções que tinha à sua disposição, menos ainda é possível determinar a carga penal que lhe corresponde (2011, p. 47). 
Tal posicionamento demonstra claramente a dúvida existente dentro do direito penal em adequar seus dogmas as novas descobertas da neurociência, tendo em vista que a culpabilidade seria baseada e entendida atualmente como a reprovabilidade sobre a conduta voluntária do autor, e estas descobertas alterariam esta constatação, não podendo ser imputada ao agente uma reprovação se não é possível determinar o grau de voluntariedade na conduta de controle do resultado por ele realizada e, principalmente, quando é possível indicar que essa voluntariedade não existe.

No meio jurídico é explícito que diversos autores se posicionam sobre as influências da neurociência sobre o direito penal, expondo, inclusive, haver uma crise neste sistema devido aos resultados colhidos de apurações sobre a mente do ser humano e a forma como ele se porta nas diferentes situações de seu cotidiano. Expondo opiniões contrarias ou favoráveis, é comprovado que a interligação entre neurociência e direito penal está se difundindo entre os estudiosos, tornando-se imperioso tratar de todas as ramificações deste tema.

\subsection{Tendências doutrinárias e pressupostos sobre a (im)possibilidade de alteração do entendimento da culpabilidade penal}

O direito deve ser uma ciência aberta, sempre se comunicando com as demais áreas que, de alguma forma, influenciam suas orientações e postulados. No momento em que estes âmbitos de conhecimento inovam em suas experiências e trazem descobertas que afetam o ordenamento jurídico, os operadores do direito devem se posicionar, apresentando suas opiniões sobre a aplicabilidade dessas premissas. Do mesmo modo ocorreu com os avanços da neurociência, causando diversas opiniões entres os penalistas em como a culpabilidade seria afetada.

Marina Cerqueira dispõe sobre a necessidade que o direito possui em estar em constante atualização e que necessita dar espaço para discutir os questionamentos trazidos pela neurociência ao ressaltar que:

\footnotetext{
Negar as relevantes descobertas neurocientíficas sobre o funcionamento do cérebro humano pode parecer uma postura de quem prefere viver na "sua própria bolha" e completamente alheia à evolução científica do mundo. Dessa mesma forma, admitir um Direito Penal que não dialogue com tais pesquisas revela a tentativa de afirmação de um sistema fechado que não precisa se comunicar com os demais, o que, de igual modo, se demonstra contraproducente (2014, p. 96).
} 
Seguindo a linha de abranger as descobertas da neurociência dentro do direito penal os doutrinadores começaram a elaborar suas conclusões, tendo convicções que variam, basicamente, se a culpabilidade realmente precisa sofrer uma alteração em seu conceito, se a neurociência deve influir neste conceito e se as descobertas seriam suficientes para alterar a compreensão de culpabilidade como é tida hoje.

A maior parte das críticas à influência da neurociência permeiam na consequência de reconhecer a ausência de liberdade dentro do direito. Ao se entender que o ser não é livre para realizar a escolha de seus atos, este indivíduo não poderia sofrer uma pena (privativa de liberdade ou restritiva de direitos) sob o ato ilícito realizado, mas sim medida de segurança. Considerando, por sua vez, que todos os seres humanos são determinados em suas decisões e não poderiam responder por seus atos ilícitos, poder-se-ia prever aqueles que são voltados ao crime e novamente haveria a condução ao antigo pensamento lombrosiano onde todos os indivíduos deveriam ser analisados como forma de prevenir os delitos com a aplicação de medidas de segurança de forma preventiva.

A consequência desta análise seria a possível volta do direito penal do inimigo, teoria trazida por Jakobs (2009), com aplicação de medidas de segurança àqueles que tiverem potencial para o cometimento de delitos.

Sebástian Mello (2014, p. 94) indica que Cristian Jager traz à tona seu receio quanto reconhecimento da ausência de liberdade humana, pois a compreensão dos seres como máquinas acabaria com os pressupostos do Estado Democrático de Direito e do princípios como o da dignidade da pessoa humana, ao discorrer que "um direito penal sem a ideia de vontade livre poderia conduzir à dissolução da ideia de dignidade da pessoa humana, que não pode existir sem a ideia de liberdade".

Divagam os doutrinadores também pela possibilidade de erros advindos de sentenças condenatórias face a ausência de tecnologias suficientes para demonstrar se o agente punido agiu por determinações neurológicas.

Maria Luiza Gorga e Guilherme Lobo Marchiorini (2015) fazem uma pequena metáfora para explicar este ponto: comparam a culpabilidade como uma régua, estando em uma ponta aquele indivíduo que aparentemente não possui problemas mentais ou neurológicos e será 
considerado imputável. Na outra ponta, estarão aqueles que foram apontados como carecedores de voluntariedade nos seus atos, sendo, consequentemente inimputáveis de todos os crimes que cometerem. Com o avanço da tecnologia e, principalmente, com o interesse da política criminal em analisar aqueles que chegam ao seu alcance por terem cometido delitos, a régua poderá pender para um dos lados, muito provavelmente indo em direção à conclusão de que todas as ações são causais.

Alguns autores fundamentam suas posições citando que sim, o direito deve estudar e compreender as novas concepções da neurociência quanto ao cérebro humano mas apenas para, como dita Eduardo Demetrio Crespo

Conseguir um Direito penal mais democrático que não se isola na 'torre de marfim' de um pressuposto metafísico claramente contrário ao que outras ciências tem a dizer sobre o cada vez mais demonstrado caráter condicionado/determinado da conduta (2014, p. 37).

Continua o autor (2014) citando que as inovações neurocientíficas não têm capacidade para mudar, em sua totalidade, os paradigmas entendidos hoje no direito Penal, mas servem para buscar soluções positivas ao autor do fato, tendo como consequência o aumento no número de casos de inimputabilidade ou semi-imputabilidade. Finaliza expondo que, se o direito concluir pela aplicação das teses neurocientíficas quanto a liberdade pode-se culminar em uma política criminal com características de crueldade, tendo em vista que a punição se voltaria completamente ao resultado e não ao que levou a ele.

Tratando a influência da neurociência no direito penal com uma metáfora chamando-a de canto da sereia, tendo em vista ser um discurso que prende o leitor e o faz interessar pelas suas constatações, Winfried Hassemer $(2014$, p. 2) diz que os operadores do direito, em especial os penalistas, devem procurar escutar os posicionamentos e descobertas dos neurocientistas para que, tendo consciência do que tratam, não se levem por suas exposições.

O supracitado autor, ao discorrer sobre o assunto, teceu diversas críticas à neurociência mas não deixou de reconhecer que, em momentos anteriores, principalmente quanto à culpabilidade, o direito conversou com as demais ciências naturais. No entanto, as novidades lançadas pelas ciências empíricas devem ser analisadas com cuidado, tendo em vista que com novos mecanismos de pesquisas e atualizações tecnológicas suas constatações estão em 
constante confirmação ou negação, não trazendo ao direito a segurança necessária e característica deste ramo.

Hassemer expõe, ainda, sobre as consequências da aferição de que não somos, como seres humanos, pautados pela liberdade e as decorrências deste fardo na sociedade:

Quem - pelas razões que for - negue que os seres humanos podem ser responsáveis pelo que fazem, elimina uma peça-chave não só de nosso ordenamento jurídico, mas também de nosso mundo. Vulnera o fundamento normativo de nosso trato social, o reconhecimento como pessoas. A base desse reconhecimento é a expectativa recíproca de que nossos congêneres não nos veem como um sistema composto por osso, músculos e nervos, mas nos percebem também como pessoa e se conduzem em função dessa percepção (2014, p. 11).

Conclui o autor (2014, p. 7) por expressar que o direito, especialmente na seara penal, deve superar as constatações advindas da neurociência porque não é ela a única área responsável por falar de liberdade, exprimindo ainda que "muito menos, [será a única] a dar a última palavra”. Além disso, entende que a superação deverá ser feita de forma pacífica tendo em vista que os dogmas de responsabilidade e imputação penal não residem apenas dentro da sabedoria da biologia, mas sim em razão de preceitos sociais.

Paulo Busato demonstra seu distanciamento em aceitar as influências de áreas como a neurociência no direito ao fazer uma crítica às ciências empíricas citando que "as ciências que trabalham com o método empírico não poderiam afirmar se existe ou não liberdade, ao menos, em sentido jurídico, afinal, trata-se de lógicas de pesquisa completamente diferentes” (2014, p. 66). Ainda cita o autor que, por entender que o conceito de culpabilidade não é pautado diretamente sobre a existência ou não do livre-arbítrio, as pesquisas de Libet não afetariam de forma alguma este conceito.

Maria Luiza Gorga e Guilherme Lobo Marchiorini coadunam com o posicionamento externado por Busato ao afirmarem seguir as linhas do direito alemão, que entende que a culpabilidade é uma construção social e, por esta razão, não seria influenciada pelas questões suscitadas pela neurociência, não importando, ao final, se a liberdade humana existe ou não. Citam, explicitando o supramencionado posicionamento que:

Estando a culpabilidade dotada de um conceito funcional, esta é uma instituição social determinada de acordo com as necessidades da prevenção geral positiva, sendo portanto irrelevante saber se todos os indivíduos estão ou não pré-determinados em seus comportamentos, posto que estes - independente de seus processos neuronais ou 
outros fatores - não tem o condão de alterar as necessidades de controle social que a teoria da culpabilidade visa suprir (2015, p. 107).

Porém, em continuidade de seus estudos, os autores explanam a necessidade de construção de um novo conceito de culpabilidade sendo este mais funcional. A partir desta necessidade trazem a possibilidade de agentes, condenados anteriormente pelo atual conceito de culpabilidade, serem agora absolvidos, face a mudança no entendimento decorrente dos avanços neurocientíficos. Finalizam seus pensamentos deixando claro que não deve o direito resistir as influências da neurociência por receio de ter seus dogmas considerados errados e também pela proposta de que a culpabilidade, de qualquer modo, manterá seu objetivo de dar a possibilidade da sociedade punir aquele que agiu contra as leis.

Na opinião de Gorga e Marchioni (2015, p.124), Gunther Jakobs é mais um estudioso que assume ser a culpabilidade fruto de uma construção social entendendo, também, pela não influência da descoberta da ausência de liberdade sob o conceito de culpabilidade.

Jakobs defende que a "culpabilidade é a falta de fidelidade ao direito manifestada" (2012, p. 50), e aquela está associada a liberdade, contudo não uma liberdade de vontade, como é a do livre arbítrio, mas sim como uma liberdade de autodeterminar suas próprias escolhas.

Este autor, apesar disso e como forma de resposta as pesquisas neurocientíficas, defende que a culpabilidade seja substituída pela prevenção geral - aquela que, dentre as funções da pena, visa intimidar a sociedade para que atue nos ditames da lei, desestimulando, por consequência, práticas criminosas.

Nas lições de Marina de Cerqueira Sant'anna, reforçando tal análise:

Nesse contexto [apresentado por Jakobs], a culpabilidade perde a sua importância e seu conteúdo praticamente desaparece, sendo caracterizada como o simples dever de fidelidade à norma e limitada ao necessário sob o ponto de vista preventivo, tendo em vista que será orientada pela expectativa organizacional e pela prevenção geral $(2014$, p. 251).

Este posicionamento de Jakobs é diretamente criticado por Sebástian Borges de Albuquerque Mello por entender o autor que a utilização de teorias preventivas como forma de impedir o cometimento de outros delitos poderia causar diversos casos de punições indiscriminadas e opressoras. Expõe que "em nome da prevenção pura e simples, seriam admitidas medidas desproporcionais violadoras da dignidade da pessoa humana" (2014, p. 95). 
Sebástian Borges de Albuquerque Mello (2014) ainda reforça que a utilização da teoria preventiva para dar razão as novidades advindas da neurociência não leva em consideração que, do mesmo modo que o infrator é determinado a agir, serão os juízes, membros do Ministério Público, peritos e demais envolvidos no litígio penal determinados em suas condutas e decisões.

José Roberto Wanderley de Castro e Fernando Antônio Alvez de Souza (2014) demonstram apreensão na possibilidade de retorno das ideias trazidas pelo direito penal do autor, causado pelas influências das já citadas pesquisas da neurociência. Indicam que a aplicação de uma teoria baseada exclusivamente no determinismo poderia proporcionar uma reformulação de toda a teoria da pena, o que não seria plausível para o atual momento da política criminal.

Uma das análises a qual se deve ter mais atenção é a trazida por Fabio André Guaragni e Rodrigo Régnier Chemim Guimarães (2014) que, em seus termos, indicam que a situação em que a experiência de Libet foi realizada tem um grande distanciamento das situações que são consideradas relevantes para o ordenamento jurídico. Os resultados encontrados quando se mede as sinapses cerebrais de alguém ao pedir para esta pessoa escolher uma letra ou decidir por apertar o botão A ou B serão, sem qualquer sombra de dúvida, diferentes se analisar o cérebro de um indivíduo no momento em que ele tomou a decisão de matar alguém (homicídio) ou subtrair, mediante grave ameaça ou violência, coisa alheia móvel (roubo).

As experiências que concluíram pela ausência de livre-arbítrio tiveram como base movimentos manuais simples. Libet pediu para que suas cobaias pressionassem um botão quando sentissem vontade, Soon e seus colaboradores requisitaram que pessoas escolhem uma letra de sua livre escolha. Em ambas as situações, há de se considerar, que seriam realizadas decisões impessoais que não poderiam de forma alguma afetar diretamente a vida dos indivíduos submetidos aos testes.

Possuem razão Guaragni e Guimarães ao ditarem que "a decisão pela prática de um homicídio é, certamente, algo que transcende essa simplificação" (2014, p. 189) que foram as experiências neurocientíficas analisadas neste trabalho. Há de se convir que os atos realizados nos experimentos caracterizam situações indiferentes para a vida daquelas pessoas, não podendo servir de parâmetro para comparar com atos relevantes para o direito. 
É indiscutível a natureza de ultima ratio do direito penal, sendo o último recurso a ser utilizado dentro do direito para punir aquelas condutas que ferem os bens jurídicos considerados mais importantes. Descarta-se a generalização, o zelo que se deve ter em sua aplicação deve ser mantido a não se contaminar por experimentos, diga-se de passagem, de altíssima grandeza inclusive para as ciências sociais, não apenas humanas, mas uma mudança de perspectiva na ratio que envolve a teoria do delito deve ser trabalhada com todo cuidado necessário, pois entre o agir voluntário (ou não) do apertar de botões e práticas que podem envolver aperto de gatilhos tem uma enorme distância.

Pelas razões acima explanadas entende-se o motivo do distanciamento dos doutrinadores em aceitar o acesso dos resultados advindos da neurociência para o direito penal. As pesquisas realizadas trabalharam com situações totalmente desconexas das analisadas dentro do direito e, deste modo, entende-se o porquê da opinião geral ser no sentido de que estas descobertas servem para iniciar um debate e uma maior análise sobre o comportamento humano, mas não são suficientes para alterar conceitos como o da culpabilidade penal.

Seja pelo receio de abrigar uma teoria do determinismo puro dentro do direito ou pela convicção de que a culpabilidade não é pautada pela liberdade, mas uma construção social, os doutrinadores demonstram posições contrárias à agregação dos preceitos quanto à ausência de livre-arbítrio dentro do direito, optando, ao menos ainda, pela manutenção dos conceitos existentes e utilização destas descobertas para outras situações pontuais, porém não menos arriscadas como o controle prévio dos indivíduos, o que recairia em uma discussão ética.

O pesquisador Ithzak Fried (RODRÍGUEZ, 2018, p. 28), que refez o experimento de Libet, porém com eletrodos no cérebro, conseguindo prever com $80 \%$ de precisão em que momento o paciente tomaria a decisão de se mover.

Mais ainda assustador podem ser os estudos sobre a optogenética, desenvolvida por Karl Deisseroth em 2005, que com experiências utilizando condutores fotossensíveis expõem os neurônios a flashes de luz que enviam íons positivos e podem controlar neurônios específicos, conseguindo fazer um rato alterar seus passos de acordo com a luz inserida no cérebro (RODRÍGUEZ, 2018, p. 34), aquilo que Reinhard Merkel chamará de Enhancement (2011, p. 51), ou artificial desenvolvimento do cérebro. 


\section{CONCLUSÃO}

Ao longo do desenvolvimento do direito penal, os conceitos e as perspectivas referentes a culpabilidade sofreram diversas alterações. Além de acompanhar mudanças culturais da sociedade, necessitou também relacionar-se ao o progresso das demais ciências, principalmente aquelas que lidam com o comportamento humano, como no caso de nossa abordagem a neurociência.

A necessidade de uma análise sobre a atual aplicabilidade da culpabilidade penal se dá pela crescente discussão quanto a dicotomia existente entre o livre-arbítrio e o determinismo, aflorada com as descobertas neurocientíficas sobre a liberdade (autonomia) do ser humano, mas também porque os próprios operadores do direito passaram direcionar seus estudos a essa perspectiva interdisciplinar.

Através da evolução das teorias da culpabilidade foram modificados, porém não excluídos, os pensamentos que a tratavam apenas como um vínculo psicológico entre a conduta e o resultado, aquele que previa um juízo de censura após análise de todo o conjunto que envolve o agente delituoso, o que defendia a ideia da voluntariedade, prevendo a culpabilidade como um fenômeno social. Todas estas, hoje, indicam ser culpabilidade o juízo de reprovabilidade sobre a conduta do agente que, tendo a possibilidade de escolher como agir, escolheu atuar contra as normas jurídicas.

Por ter a liberdade (autonomia) como base, não houve como evitar uma instabilidade dessa noção sobre culpabilidade, em face a presença de experiências que trouxeram uma constatação de que o livre agir não existe, no sentido de escolha sobre a ação, pois os atos decisórios decorrem de impulsos cerebrais inconscientes.

A neurociência trouxe de volta a clássica dicotomia entre livre-arbítrio e determinismo, levando os estudiosos a discutirem suas reais influencias no direito. Analisando estas discussões observa-se que, majoritariamente, os doutrinadores distanciam-se da possibilidade de mudar a concepção de culpabilidade face as novas descobertas, apesar de não descartarem sua importância para que o comportamento humano seja melhor entendido. 
Este posicionamento se dá principalmente pelo fato de que os resultados das pesquisas não podem ser inseridos diretamente ao campo das regulações do direito, nos mesmos moldes de inferências pela neurociência, tanto pelo fato de serem ciências com objetos de análise diversos, por mais interligados que o sejam, quanto pela forma que estas pesquisas foram realizadas, distanciando-se de situações as quais o direito poderá interferir.

As pesquisas realizadas não foram direcionadas para o direito penal, seus objetivos eram, simplesmente, analisar as sinapses do cérebro no momento de uma decisão qualquer. E aqui se vê a maior dificuldade em confirmar nossas hipóteses iniciais, sendo o ponto central da impossibilidade de utilização destas conclusões para alteração da culpabilidade penal.

As condutas analisadas pelas ciências criminais possuem um maior grau de complexidade àquelas analisadas pelos neurocientistas que, ressalte-se, ainda deixam diversos questionamentos sem respostas quanto as recentes descobertas aqui estudadas. Assim, riscos de aceitar as novas premissas da neurociência no direito vão além de uma alteração da culpabilidade, pois além de interferir no conceito de crime que é analítico, consequentemente geraria consequências na aplicação da pena, ressaltando que estamos diante de esfera mais lesiva do direito, o que protege os bens jurídicos mais relevante, mas também infere as sanções mais graves.

Não há possibilidade real de utilizar-se, no direito, pelo menos ainda, de experiências distanciadas do viés emocional, haja vista ser uma ciência que julga comportamentos humanos em ações baseadas em elementos orientados por critérios de subjetividade. Por esta razão, as descobertas aqui expostas não podem ser levadas como a última e mais seguro critério capaz de reformar todo o sistema jurídico como hoje é conhecido.

No cenário atual, a resposta que o direito penal pode oferecer para abarcar em seus postulados as descobertas da neurociência seria utilizá-las para análises comportamentais, que auxiliem na determinação da imputabilidade, trazendo mais coerência em decisões que decretam medidas de segurança por exemplo, inclusive para ações prognósticas, porém com todo o cuidado em relação a ações preventivas como no caso do Enhancement, aproximando assim uma pretensa segurança jurídica a devida precaução em relação ao uso de medidas protetivas e repressivas sobre esses indivíduos. 
O direito deve manter-se sempre aberto as novidades advindas das demais ciências, porém deve primeiro se preocupar em manter a infalibilidade de seus postulados, bem como a certeza de que as inovações trazidas são consolidadas entre os estudiosos e que serão suficientes a ponto renovar positivamente, no que tange a garantias fundamentais, entendimentos pacificados ao longo do tempo.

\section{REFERÊNCIAS BIBLIOGRÁFICAS}

ASUA, L. J. de. Tratado de derecho penal: concepto del derecho penal y de la criminologia, historia y legislación penal comparada. Buenos Aires: Editorial Losada, 1950.

BITENCOURT, C. R. Tratado de Direito Penal: parte geral. São Paulo: Saraiva, 2009.

BRANDÃO, C. Curso de Direito Penal. Rio de Janeiro: Editora Forense, 2008.

Teoria jurídica do crime. 4. ed. São Paulo: Atlas, 2015.

BRASIL. Código Penal. Decreto-Lei nº 2.848/40. Vade Mecum. São Paulo: Saraiva, 2017.

BUSATO, P. C. Apontamentos sobre o dilema da culpabilidade penal. Revista Liberdades, $\mathrm{n}$. 8. p. 1-87. São Paulo: Editora IBCCRIM, set. dez., 2011.

; HUAPAYA, S. M. Introdução ao Direito Penal: fundamentos para um Sistema Penal Democrático. 2. ed. Rio de Janeiro: Lumen Juris, 2007.

CRESPO, E. D. "Compatibilismo humanista": uma proposta de conciliação entre Neurociências e Direito Penal. In: BUSATO, P. C. (org.). Neurociência e Direito Penal. São Paulo: Editora Atlas, 2014.

FREUD, S. A interpretação dos sonhos. Tradução de Luiz Alberto Hanns. Rio de Janeiro: Imago, 1990.

Totem e tabu: algumas concordâncias entre a vida psíquica dos homens primitivos e a dos neuróticos. Tradução de Paulo César de Souza. São Paulo: Penguin Classics Companhia das Letras, 2013.

GRECO, R. Curso de Direito Penal: parte geral. 16. ed. Rio de Janeiro: Impetus, 2014. 
GUARAGNI, F. A. GUIMARÃES, R. R. C. Neurociência, livre-arbítrio e Direito Penal: precipitação científica e alternativas para sustentação da culpabilidade. In: BUSATO, P. C. (org.). Neurociência e Direito Penal. São Paulo: Editora Atlas, 2014.

GORGA, M. L.; MARCHIONI, G. L. Liberdade da vontade, Neurociência e Culpabilidade. In: Revista Brasileira de Ciências Criminais. V. 114, ano 23. p. 99-129. São Paulo: Editora RT, mai. jun., 2015.

HASSEMER, W. Neurociências e Culpabilidade em Direito Penal. Tradução de Paulo César Busato. In: BUSATO, P. C. (org.). Neurociência e Direito Penal. São Paulo: Editora Atlas, 2014.

JAKOBS, G. Fundamentos do direito penal. Tradução de André Luís Callegari. 2. ed. São Paulo: Editora Revista dos Tribunais, 2012.

Tratado de direito penal: teoria do injusto penal e culpabilidade. Tradução de Geraldo de Carvalho [et al.]. Belo Horizonte: Del Rey, 2009.

JIMENEZ, J. F. L. En defesa de la culpabilidade: analises en relacion a las criticas de las neurociencias. Revista de Derecho. Escuela de Postgrado n. 5. p. 55-84. Jul. 2014.

KANDEL, E. R.; JESSEL, T. M.; SIEGELBAUM, S. A.; HUDSPETH, A. J. Tradução de Ana Lúcia Severo Rodrigues [et al.]. Princípios de neurociências. 5. ed. Porto Alegre: AMGH, 2014.

LIBET, B. Do we have free will? In the volitional brain. Towards a neuroscience of free will. Exeter-UK: Imprint Academic, 2000.

MARQUES, O. H. D. Fundamentos da pena. 2. ed. São Paulo: WMF Martins Fontes, 2008.

MELLO, S. B. de A. Culpabilidade e neurociências. Entre problemas reais e imaginários. In: BUSATO, Paulo Cézar (org.). Neurociência e Direito Penal. São Paulo: Editora Atlas, 2014.

MERKEL, R. Novedosas intervenciones del cerebro: mejora de la condición humana mental y limites del derecho penal. Tradução de Dyrk Sturma. Revista de Derecho Penal - Imputación, causalidad y ciência III, Santa Fé. n. 1, 2011.

PRADO, L. R. Curso de Direito Penal Brasileiro. 13. ed. São Paulo: Editora Revista dos Tribunais, 2014.

RODRÍGUEZ, V. G. Livre arbítrio e direito penal: revisão frente aos aportes da neurociência e a evolução dogmática. São Paulo: Marcial Pons, 2018.

SANT'ANNA, M. de C. Culpabilidade, livre-arbítrio e neurociências. In: BUSATO, P. C. (org.). Neurociência e Direito Penal. São Paulo: Editora Atlas, 2014.

Direito Penal: parte geral. 4. ed. Curitiba: ICPC: Conceito Editorial, 2010 
Neurociências e Culpabilidade. 2014. Dissertação (Mestrado em Direito) Universidade Federal da Bahia, (Mestrado em Direito). Disponível em: $<$ https://repositorio.ufba.br/ri/bitstream/ri/16611/1/Disserta\%C3\%A3o.Marina\%20Cerqueira. pdf>. Acesso em: 2 fev. 2017.

SANTOS, J. C. dos. Direito Penal: parte geral. 3. ed. Curitiba: Lumen Juris, 2008.

TAVARES, J. Teorias do delito. São Paulo: Editora Revista dos Tribunais, 1980.

TÚNEZ FIÑANA, I.; PASCUAL LEONE, Á. Estimulacion magnética transcraneal y neuromodulacion: presente y futuro em neurociências. Barcelona: Elsevier, 2014.

WELZEL, H. El nuevo sistema del Derecho Penal. Tradução de José Cerezo Mir. Barcelona: Ariel, 1964.

O novo sistema jurídico penal: uma introdução à doutrina da ação finalista. Tradução de Luís Régis Prado. 3. ed. São Paulo: Editoria Revista dos Tribunais, 2011.

ZAFFARONI, E. R.; PIERANGELI, J. H. Manual de Direito Penal Brasileiro: parte geral. 8. ed. São Paulo: Editora Revista dos Tribunais, 2009.

Data de Submissão: 11/05/2020

Data de Aceite: 01/09/2020 